\title{
SUDUT PANDANG SEBAGAI UNSUR FIKSI KARYA SASTRA
}

\author{
Julfahnur \\ Fakultas Sastra, Universitas Muslim Indonesia \\ Jalan Urip Sumoharjo KM 5, Makassar \\ julfahnurnur@gmail.com
}

\begin{abstract}
Abstrak: Sudut pandang, point of view, viewpoint, merupakan salah satu unsur fiksi yang oleh Stanton digolongkan sebagai sarana cerita literary device. Sudut pandang haruslah diperhitungkan kehadirannya, bentuknya, sebab pemilihan sudut pandang akan berpengaruh terhadap penyajian cerita. Reaksi afektif pembaca terhadap sebuah cerita fiksipun dalam banyak hal akan dipengaruhi oleh bentuk sudut pandang. Sudut pandang pada hakikatnya merupakan strategi, teknik, siasat, yang secara sengaja dipilih pengarang untuk mengemukakan gagasan dan cerita. Menurut Booth mengemukakan bahwa sudut pandang merupakan teknik yang dipergunakan pengarang untuk menemukan dan menyampaikan makna karya artistiknya, sehingga dapat sampai dan berhubungan dengan pembaca. Dengan teknik yang dipilihnya diharapkan pembaca dapat menerima dan menghayati gagasa-gagasan dan karenanya teknik boleh dikatakan efektif. Sudut pandang cerita itu sendiri secara garis besar dapat dibedakan dalam dua macam: persona pertama, first-person, gaya "aku", dan persona ketiga, third-person, gaya "dia". Adapun macam-macam sudut pandang: (1) sudut pandamg persona ketiga "Dia". Sudut pandang "dia" dapat dibedakan dalam dua golongan berdasarkan tingkat kebebasan dan keterikatan pengarang dengan bahan ceritanya yaitu "Dia" mahatau dan "Dia" terbatas,"Dia" sebagai pengamat; (2) sudut pandang persona pertama "Aku" berdasarkan peran dan kedudukan dalam cerita dibagi menjadi dua golongan yaitu "Aku" Mahatau dan "Aku" tokoh tambahan; (3) sudut pandang persona kedua: "Kau"; dan (4) sudut pandang campuran.
\end{abstract}

Kata Kunci : Sudut Pandang, Fiksi, Satra

\section{PENDAHULUAN}

Karya sastra merupakan sebuah karya yang pada hakikatnya dibuat dengan mengedepankan aspek keindahan di samping keefektifan penyampaian pesan. Karya sastra dapat membentuk suatu kepribadian karena di dalamnya memuat amanat tentang moral, mengembangkan imajinasi dan kreativitas dalam pembelajaran sebagai alternative bahan ajar yang berbasis pendidikan karakter. Aspek keindahan tersebut sengaja dibentuk oleh pengarang dengan memanfaatkan potensi bahasa yang digali dari kekayaan bahasa setempat. Aspek keindahan ini juga dipergunakan oleh pengarang agar dapat memberikan daya tarik kepada sesuatu karya sastra sehingga mampu memikat para pembacanya. Setiap kegiatan manusia tidak terlepas dari bahasa. Bahasa juga dipergunakan untuk menanggapi apa yang terjadi di sekitar atau peristiwa yang terjadi.

Pada hakikatnya karya sastra adalah suatu pengungkapan kehidupan lewat bentuk bahasa. Hal ini sesuai dengan pendapat Teeuw (1984:22) yang mengatakan bahwa, "usaha lain untuk mendapatkan batasan sastra sebagai suatu gejala umumyaitu dengan mendekati dari namanya meskipun biasanya batasan itu tidak sempurna karena harus diperluas dan diperketat apabila gejala itu akan dibicarakan secara ilmiah. Namun manfaat 
tinjauan dari pemakaian bahasa sehari-hari sebagai titik tolak cukup memadai”.

Karya sastra lahir karena adanya daya imajinasi yang di dalamnya terdapat ide, pikiran dan perasaan seorang pengarang. Daya imajinasi inilah yang mampu membedakan antara karya sastra satu dengan karya sastra lainnya. Hal ini disebabkan masing-masing pengarang mempunyai kemampuan daya imajinasi dan kepandaian untuk mengungkapkan ke bentuk tulisan yang berbeda-beda.

Kehadiran karya sastra tidak akan lepas dari identitas pengarangnya sebab sebuah karya fiksi, bagaimanapun proses pembuatannya, tetap saja bersumber dari kehidupan masyarakat penciptanya. Banyak aspek yang meliputi kehidupan pengarang, tetapi semua itu tentunya melalui pikiran dan perenungan yang mendalam sehingga akan diungkapkan tidak semua persis dengan apa yang terjadi di masyarakat.

\section{PEMBAHASAN}

\section{Sudut Pandang Sebagai Unsur Fiksi}

\section{Hakikat Sudut Pandang}

Sudut pandang, point of view, viewpoint merupakan salah satu unsur fiksi yang oleh Stanton digolongkan sebagai sarana cerita literary device. Walau demikian, hal itu tidak berarti bahwa perannya dalam fiksi tidak penting. sudut pandang haruslah diperhitungkan kehadirannya, bentuknya, sebab pemilihan sudut pandang akan berpengaruh terhadap penyajian cerita. Reaksi afektif pembaca terhadap sebuah cerita fiksipun dalam banyak hal akan dipengaruhi oleh bentuk sudut pandang. Sudut pandang dalam teks fiksi mempersoalkan: siapa yang menceritakan atau dari posisi mana (siapa) peristiwa dan tindakan itu dilihat.
Sudut pandang, point of view, menunjuk pada cara sebuah cerita dikisahkan. Ia merupakan cara atau pandangan yang dipergunakan pengarang sebagai sarana untuk menyajikan cerita dalam sebuah karya fiksi kepada membaca (Abrams, 1999:231). Dengan semikian, sudut pandang pada hakikatnya merupakan strategi, teknik, siasat, yang secara sengaja dipilih pengarang untuk mengemukakan gagasan dan cerita. Segala sesuatu yang dikemukakan dalam cerita fiksi memang milik pengarang, yang antara lain berupa pandangan hidup dan tafsirannya terhadap kehidupan. Namun, kesemuanya itu dalam cerita fiksi di salurkan lewat sudut pandang tokoh, lewat kacamata tokoh cerita yang sengaja dikreasikan.

\section{Pentingnya Sudut Pandang}

Dewasa ini pentingnya sudut pandang dalam teks fiksi tidak lagi diragukan orang. Sudut pandang dianggap sebagai salah satu unsur fiksi yang penting dan menentukan. Kesemuanya itu di mulai setelah Henry James yang novelis sekaligus esais Amerika itu menulis esai tentang sudut pandang secara menyakinkan, dan belakangan esai-esainya di kumpulkan dan terbit dengan judul The Art of Novel (1934). Selanjutnya, Percy Lubbock mengembangkan esai James dalam The Craf of Fiction (1926) secara lebih luas dan rinci dengan analisis yang mendetail tentang efek penggunaan sudut pandang dalam berbagai cerita fiksi, khususnya karya James. Setelah itu, sudut pandang masuk menjadi salah satu unsur penting dalam teori fiksi modern dan segera menjadi topik topic of the day (Abrams, 1999:231; Forster, 1970:85-86; Teeuw, 1988:170).

Sebelum pengarang menulis cerita, mau tidak mau, ia harus telah memutuskan 
memilih sudut pandang tertentu. Ia harus mengambil sikap menuliskan ceritanya dengan sudut pandang orang pertama atau ketiga, masing-masing dengan berbagai kemungkinannya, atau bahkan keduanya sekaligus.

Pemilihan sudut pandang tertentu memang membutuhkan konsekeunsi di samping ada berbagai kemungkinan teknis penyajian sudut pandang yang dapat dimanfaatkan dan sekaligus dapat dikreasikan oleh pengarang. Teknik penyajian sudut pandang tertentu akan lebih efektif jika diikuti oleh pemilihan bentuk gramatika dan terotika yang sesuai. Masalah keefektifan penggunaan sudut pandang tidak akan telepas dari kemampuan pengarang menyiasati ceritanya, membuat cerita menjadi menarik sehingga mampu "memaksa" pembaca untuk memberikan empatinya.

\section{Penekanan Sudut Pandang}

Penulisan cerita fiksi, seperti pada umumnya penulisan teks kesastraan tidak pernah lepas dari penyimpangan dan pembaharuan, baik hanya meliputi satudua elemnen tertentu maupun sejumlah elemen sekaligus dalam sebuah karya. Adanya penyimpangan dan pembaharuan dalam sebuah karya sastra merupakan hal yang esensial, artinya pengarang melakukan penyimpangan agar karyanya di anggap lain. Penyimpangan dan atau pembaharuan pastilah ada makna dan tujuannya. Keadaan ini mungkin dikarenakan pengarang ingin menunjukkan sesuatu secara lain, melihat sesuatu dari dimensi lain atau ingin menekankan apa yang dikemukakannya.

Hal ini berlaku pula dalam pemilihan sudut pandang. Pengarang dapat saja melakukan penyimpangan (mungkin pembaharuan) terhadap penggunaan sudut pandang dari yang telah biasa banyak digunakan orang. Dengan cara itu, ia ingin menarik perhatian pembaca sehingga segala sesuatu yang diceritakan dapat lebih memberikan kesan.

Misalnya, sudut pandang berasal dari tokoh anak. Dalam memandang dan mereaksi suatu adengan, misalnya adengan "dewasa" reaksi dan pandangan anak tentulah berbeda dengan orang dewasa. Bagi anak, adengan itu barangkali merupakan sesuatu yang lucu, tetapi bagi orang dewasa bersifat erotis. Namun pembaca fiksi adalah dewasa sehingga mereka pun dapat membayangkan adengan erotis itu lewat sudut pandang anak walau si anak itu sendiri tidak memahami makna yang terkandung didalamnya.

\section{Macam-macam Sudut Pandang}

Sudut pandang dapat banyak macamnya tergantung dari sudut mana ia dipandang dan seberapa rinci ia dibedakan. Friedman (Stevick, 1967:118) mengemukakan adanya sejumlah pertanyaan yang jawabnya dapat dipergunakan untuk membedakan sudut pandang. Pertanyaan sebagai berikut:

(a) Siapa yang berbicara kepada pembaca (pengarang dalam persona ketiga atau pertama, salah satu pelaku dengan "aku" atau seperti tidak seorang pun)?

(b) Dari posisi mana cerita itu dikisahkan (atas, tepi, pusat, depan, atau berganti-ganti)?

(c) Saluran informasi apa yang dipergunakan narator untuk menyampaikan ceritanya kepada pembaca (kata-kata, pikiran, atau persepsi pengarang; kata-kata, tindakan, pikiran, perasaan, atau persepsi tokoh)? 
(d) Sejauh mana narator menempatkan pembaca dari ceritanya (dekat, jauh atau berganti-ganti)?

\section{Sudut Pandang Persona Ketiga "Dia"}

Pengisahan cerita yang mempergunakan sudut pandang persona ketiga, gaya "dia" narator adalah seseorang yang berada di luar cerita yang menampilkan tokoh-tokoh cerita dengan menyebut nama atau kata gantinya; ia, dia, mereka. Nama-nama tokoh cerita, khuususnya yang utama. Kerap atau terusmenerus disebut, dan sebagai variasi digunakan kata ganti. Hal ini akan mempermudah pembaca untuk mengenali siapa tokoh yang diceritakan atau siapa yang bertindak. Tokoh-tokoh itu seperti, Srintil, Kartareja, Sakarya, dan Sakum dalam Ronggeng Dukuh Paruk atau Sadeli, Maria, David, Wayne dalam Maut dan Cinta.

Sudut pandan "dia" dapat dibedakan ke dalam dua golongan berdasarkan tingkat kebebasan dan ketertarikan pengarang terhadap bahan ceritanya. Di satu pihak pengarang, narator dapat bebas menceritakan segala sesuatu yang berhubungan dengan tokoh "dia" jadi bersifat mahatahu, dipihak lain ia terikat, mempunyai keterbatasan "pengertian" terhadap tokoh "dia" yang diceritakan itu, jadi bersifat terbatas, hanya selaku pengamat saja.

\section{a. "Dia" Mahatahu}

Sudut pandang persona ketiga mahatahu dalam literatur bahasa Inggris dapat dikenal dengan istilah the omniscient point of view, third-person omniscient narrator, atau author omniscient. Dalam sudut pandang ini, cerita dikisahkan dari sudut pandang "dia", namun pengarang, narator, dapat menceritakan apa saja halhal yang menyangkut tokoh "dia". Narator mengetahui segalanya, ia bersifat mahatahu (omniscient). Ia mengetahui berbagai hal tentang tokoh, peristiwa, dan tindakan, termaksud motivasi yang melatarbelakanginya. Ia bebas bergerak dan menceritakan apa saja dalam lingkup waktu dan tempat cerita, berpindah-pindah dari tokoh "dia" yang satu ke tokoh "dia" yang lain. Menceritakan atau sebaliknya " menyembunyikan" ucapan dan tindakan tokoh, bahkan juga yang hanya berupa pikiran, perasaan, pandangan, dan motivasi tokoh secara jelas seperti halnya ucapan dan tindakan nyata (Abrams, 1999:232).

Contohnya: Dia melihat betapa Maria sekuat tenaga menjaga dirinya jangan menangis terisak-isak karena ada ibunya, dan karena ibunya telah mengatakan kepadanya, bahwa semua ini akan terjadi, dan Maria mengatakan pada ibunya bahwa dia akan kuat menahannya.

Apa yang dilakukan Maria kini? Tanya Sadeli pada dirinya sendiri. Dan Sadeli tak tahu bahwa saat itu Maria sedang terbaring di tempat tidurnya, air mata mengalir membahasi pipinya, membasahi bantalnya, dan dia mencoba menghidupkan kembali dalam ingatannya, dalam seluruh badannya apa yang pernah terjadi di tempat tidur antara dia dan Sadeli (Maut dan Cinta, 1977:245-246).

Pembicaraan di atas betapa kuatnya teknik gaya dia mahatahu untuk mengisahkan sebuah cerita. Ia merupakan teknik yang paling natural dari semua teknik yang ada dan sekaligus dikenal sebagai teknik yang memiliki fleksilibitas yang tinggi. 
b. "Dia" Terbatas "Dia" Sebagai Pengamat

Dalam sudut pandang "dia" terbatas, seperti halnya dalam "dia" mahatahu, pengarang melukiskan apa yang dilihat, didengar, dialami, dipikir, dan dirasakan oleh tokoh cerita, namun terbatas hanya pada seorang tokoh saja (Stanton, 1965:26), atau tebatas dalam jumlah yang sangat terbatas (Abrams, 1999:233). Tokoh cerita mungkin banyak, yang juga berupa tokoh "dia" namun mereka tidak diberi kesempatan untuk menunjukkan sosok dirinya seperti halnya tokoh pertama. Oleh karena itu, dalam teknik ini hanya ada seorang tokoh yang terseleksi untuk diungkap, tokoh tersebut merupakan fokus, cermin atau pusat kesadaran, center of consciousness. Berbagai peristiwa dan pandangan yang diceritakan disajikan lewat "pandangan" dan atau kesadaran seorang tokoh dan hal itu sekaligus menjadi "filter" bagi pembaca.

\section{Sudut Pandang Persona Pertama "Aku" \\ Dalam pengisahan cerita yang} mempergunakan sudut pandang persona pertama, first-person point of view. "aku", jadi gaya "aku", narator adalah seseorang ikut terlibat dalam cerita. Ia adalah si "aku" tokoh yang berkisah, mengisahkan, kesadaran dirinya sendiri, self consciousness, mengisahkan peristiwa dan tindakan, yang diketahui, dilihat, didengar, dialami, dan dirasakan, serta sikapnya terhadap orang (tokoh) lain kepada pembaca. Kita pembaca menerima apa yang diceritakan oleh si "aku" maka kita hnaya dapat melihat dan merasakan secara terbatas seperti yang dilihat dan dirasakan oleh tokoh si "aku" tersebut.

Berdasarkan peran dan kedudukan si "aku" dalam cerita, sudut pandang persona pertama dapat dibedakan dalam dua golongan. Si "aku" yang menduduki peran utama. Jadi tokoh utama protagonis dan menduduki peran tambahan jadi tokoh tambahan protagonist atau berlaku sebagai saksi.

a. "Aku" Tokoh Utama

Dalam sudut pandang teknik ini, si "aku" mengisahkan berbagai peristiwa dan tingkah laku yang dialaminya. Baik yang bersifat batiniah (dalam diri sendiri), maupun fisik (hubungan dengan sesuatu di luar dari dirinya sendiri). Si "aku" menjadi fokus, pusat kesadaran, dan pusat cerita. Segala sesuatu yang berhubungan di luar diri si "aku" peristiwa, tindakan dan orang, diceritakan hanya jika berhubungan dengan dirinya atau dianggap penting.

\section{b. "Aku" Tokoh Tambahan}

Dalam sudut pandang ini, tokoh "aku" muncul bukan sebagai tokoh utama, melainkan sebagai tokoh tambahan firstperson peripheral. Tokoh "aku" hadir untuk membawakan cerita kepada pembaca, kemudia "dibiarkan" untuk mengisahkan sendiri pengalamannya. Tokoh cerita yang dibiarkan berkisah sendiri di sebut tokoh utama karena dia yang banyak tampil, membawa berbagai peristiwa, tindakan, dan berhubungan dengan tokoh lain. Setelah tokoh utama selesai tampil, si "aku" tambahan tampil kembali dan dialah kini yang berkisah dan tampil sebagai saksi, witness saja.

\section{Sudut Pandang Persona Kedua "Kau"}

Dalam berbagai buku teori fiksi (kesastraan) jarang ditemukan sudut pandang persona kedua atau gaya "kau". Yang lazim disebut hanya sudut pandang persona ketiga dan pertama. Namun, 
secara faktual, sudut pandang persona kedua tidak jarang ditemukan dalam berbagai cerita fiksi walau hanya sekedar selingan. Artinya sudut pandang persona kedua gaya "kau" merupakan cara pengisahan yang mempergunakan "kau" sebagai variasi cara memandang oleh tokoh aku dan dia.

Dalam novel Suami, tokoh Bram yang selalu saja merasa "kalah" dari istrinya, berkali-kali muncul melihat dirinya sebagai orang lain lawan bicara, sebagai kau. Bram si tokoh "dia" kerap berintrospeksi mengajak dialog dengan diriya sendiri sebagai Bram yang lain tentang berbagai hal yang menekan perasaanya.

\section{Sudut Pandang Campuran}

Penggunaan sudut pandang dalam sebuah novel mungkin saja lebih dari satu teknik. Pengarang dapat berganti-ganti dari teknik yang satu ke teknik yang lain untuk sebuah cerita yang di tuliskannya. Kesemuanya itu tergantung dari kemauan dan kreativitas pengarang, bagaimana mereka memanfaatkan berbagai teknik yang ada demi tercapainya efektivitas penceritaan yang lebih, atau paling tidak untuk mencari variasi agar memberikan kesan lain.

Penggunaan sudut pandang campuran di dalam sebuah novel, mungkin berupa penggunaan sudut pandang persona ketiga dengan teknik "dia mahatahu" dan "dia sebagai pengamat", persona pertama dengan teknik " aku sebagai tokoh utama" dan "aku sebagai tokoh tambahan atau sebagai saksi". Selain itu, dapat pula berupa campuran antara persona pertama dan ketiga, antara "aku" "dia", bahkan kadang-kadang diselingi kata persona kedua "kau".

Campuran “Aku” dan "Dia”. Penggunaan sudut pandang campuran antara persona pertama dan ketiga, "aku" dan "dia" secara bergantian dapat kita jumpai pada beberapa novel di Indonesia. Mula-mula diceritakan dari sudut pandang "aku", namun kemudian bergantian "dia" dan kembali ke "aku". Misalnya pada novel Burung-burung Manyar, Dan Senja Pun Turun, dan Ronggeng Dukuh Paruk, Lintang Kemukus Dini Hari dan Jantera Bianglala, jika ketiganya di anggap sebagai satu kesatuan. Penggunaan kedua sudut pandang tersebut dalam sebuah novel terjadi karena pengarang ingin memberikan cerita yang lebih banyak kepada pembaca.

\section{KESIMPULAN}

Sudut pandang, point of view, menunjuk pada cara sebuah cerita dikisahkan. Ia merupakan cara atau pandangan yang dipergunakan pengarang sebagai sarana untuk menyajikan cerita dalam sebuah karya fiksi kepada membaca. Dengan semikian, sudut pandang pada hakikatnya merupakan strategi, teknik, siasat, yang secara sengaja dipilih pengarang untuk mengemukakan gagasan dan cerita. Segala sesuatu yang dikemukakan dalam cerita fiksi memang milik pengarang, yang antara lain berupa pandangan hidup dan tafsirannya terhadap kehidupan. Namun, kesemuanya itu dalam cerita fiksi di salurkan lewat sudut pandang tokoh, lewat kacamata tokoh cerita yang sengaja dikreasikan. 


\section{DAFTAR PUSTAKA}

Abrams, M.H. 1981. A Glossary of Literary Terms. New York:Holt, Rinehart and Winston.

Ardiana Zusi, Nazaruddin Kahfie, Suyanto Edi. 2014. Sudut Pandang Pencerita Dalam Novel "Padang Bulan" Karya Andrea Hirata.Jurnal Kata ( Bahasa, Sastra, dan Pembelajaran), hlm.3.

Genette, Gerald. 1980. Narrative Discourse. Oxford: Cornell University Press.

Muliadi. 2017. Buku Ajar Telaah Prosa (Sebuah Terapan). Makassar: De La Macca.

Nurgiyantoro, Burhan. 2010. Teori Pengkajian Fiksi. Yogyakarta: Gajah Mada University Press.

Rahmanto, Bernadus. 1988. Metode Pengajaran Sastra. Yogyakarta: Kanisius.

Riza Suryadi, \& Agus Nuryatin. 2017. Nilai Pendidikan dalam Antologi Cerpen Senyum Karyamin Karya Ahmad Tohari. Seloka: Jurnal Pendidikan Bahasa dan Sastra Indonesia. hlm. 315-318.

Warsiman. 2013. Membangun Pemahaman Terhadap Karya Sastra Berbentuk Fiksi (Telaah Sifat dan Ragam Fiksi Naratif). Jurnal Thaqafiyyat, 14(1), 180-183.

Mansyur, Umar. 2018. Pemanfaatan Nilai kejujuran dalam Cerpen sebagai Bahan Ajar Berbasis Pendidikan Karakter. In Mengais Karakter dalam Sastra: HISKI Makassar (pp. 330-339). https://doi.org/10.17605/OSF.IO/Z4T3Y

Mansyur, Umar. 2018. Kiat dan Teknik Penulisan Skripsi bagi Mahasiswa. INA-Rxriv. https://doi.org/10.31227/osf.io/juds7 